\title{
Allergen-driven HLA-G expression and secretion in peripheral blood mononuclear cells from allergic rhinitis patients
}

\author{
Paola Contini $^{\mathrm{a}}$, Francesco Puppo ${ }^{\mathrm{a}, *}$, Giorgio Walter Canonica ${ }^{\mathrm{b}}$, Giuseppe Murdaca ${ }^{\mathrm{a}}$, Giorgio Ciprandi ${ }^{\mathrm{b}}$ \\ a Clinical Immunology, Department of Internal Medicine, University of Genoa \& IRCCS-Azienda Ospedaliera Universitaria San Martino, 16132 Genoa, Italy \\ b Allergy and Respiratory Diseases Units, Department of Internal Medicine, University of Genoa \& IRCCS-Azienda Ospedaliera Universitaria San Martino, 16132 Genoa, Italy
}

\section{A R T I C L E I N F O}

\section{Article history:}

Received 16 July 2014

Received in revised form 21 July 2016

Accepted 10 August 2016

Available online xxx

\section{Keywords:}

HLA-G

Allergic rhinitis

CD4 T cells

Monocytes

\section{A B S T R A C T}

\section{Background}

It has been reported that soluble HLA-G serum levels are increased in patients with pollen-induced allergic rhinitis and decrease after immunotherapy. However, no functional study has been conducted so far. The aim of this study was to evaluate the membrane expression and secretion of HLA-G molecules in peripheral blood mononuclear cells from allergic rhinitis patients after in vitro incubation with the causal allergen.

Methods and results

Twenty-two allergic rhinitis patients and ten healthy subjects were enrolled. Membrane HLA-G expression was determined by flow cytometry and soluble HLA-G in culture supernatant was determined by immunoenzymatic assay. HLA-G expression was detected in CD4+ (T-helper-2) cells and monocytes after in vitro stimulation with the causal allergen but not with non specific stimuli and non causal allergens. Accordingly, the release of soluble HLA-G in culture supernatant occurred only after the stimulation with the causal allergen. Collectively, these results were confirmed by Western blot analysis.

\section{Conclusions}

The present study provides the first in vitro evidence that in allergic patients HLA-G expression and secretion is specifically induced by the causal allergen. These data may add new insights into the pathogenetic mechanisms underlying allergic inflammation and allergen specific immunotherapy.

(C) 2016 Published by Elsevier Ltd

\section{Introduction}

HLA-G is a human non-classical major histocompatibility complex (MHC) molecule mainly expressed in membrane-bound form at the fetal-maternal interface on the extravillous cytotrofoblast [1] and in placental tissue [2] where it contributes to the development of maternal tolerance to the semi-allogeneic fetus [3]. It is also physiologically expressed in certain adult tissues such as thymus [4], cornea [5], pancreas [6] and bronchial epithelial cells [7] as well as in different cells types such as activated monocytes [8] and erythroid and endothelial precursors [9]. The expression of HLA-G antigens has been recently reported in some solid tumours, transplanted organs, cutaneous inflammatory diseases and on virally infected cells in several pathological conditions $[10,11]$. HLA-G is also detectable as a soluble form (sHLA-G) in several body fluids and derives from the shedding of proteolytically cleaved surface isoforms (sHLA-G1) and/or the secretion of soluble isoforms (HLA-G5, -G6 and -G7) [12-14]. Re-

Abbreviations: sHLA-G, soluble HLA-G; Th, T helper; PBMC, peripheral blood mononuclear cells; AR, allergic rhinitis; $\mathrm{mAb}$, monoclonal antibody; MFI, mean fluorescence intensity; Tregs, regulatory $\mathrm{T}$ cells

* Corresponding author at: Viale Benedetto XV 6, 16132 Genoa, Italy.

Email address: puppof@unige.it (F. Puppo) cently it has been demonstrated that a significant proportion of sHLA-G molecules is contained in microsomes or exosomes released from cells [15-17]. Elevated levels of sHLA-G molecules have been detected in plasma of patients affected by various pathological conditions [18-23] and in cerebrospinal fluid of patients with multiple sclerosis [24].

Several immune regulatory functions have been attributed to both membrane-bound and soluble HLA-G molecules $[25,26]$. Most of them are immunosuppressive as they inhibit the cytolytic function of NK cells and CD8+ T lymphocytes [27,28], the alloproliferative response of CD4+ T cells [29], the maturation of dendritic cells [30] and the activation of $\mathrm{B}$ cells [31]. In addition, HLA-G molecules are able to trigger apoptosis in antigen-specific CD8+ $\mathrm{T}$ lymphocytes $[28,32,33]$. HLA-G seems to be involved also in the tuning of immune responses: in vitro studies indicate that incubation of peripheral blood mononuclear cells (PBMC) with HLA-G expressing cells favors a shift towards a $\mathrm{T}$ helper (Th)-2 cytokine profile, while incubation with sHLA-G protein induces an anti-inflammatory environment due to the release of inteleukin-10 [34,35] Finally, HLA-G-positive $\mathrm{CD} 4{ }^{+} \mathrm{CD} 25^{-} \mathrm{FoxP}^{+}$regulatory $\mathrm{T}$ cells have been detected in peripheral blood and in inflamed tissues [36-39].

As far as allergic diseases are concerned, which are presently considered as disorders characterized by a dysfunction of immunoregulation leading to an amplified Th-2 response [40,41], it has been re- 
ported that elevated levels of sHLA-G molecules are detected in plasma and bronchoalveolar lavage fluid of atopic asthmatics [42-45], that the production of sHLA-G in unstimulated PBMC cultures is significantly higher in subjects with occupational isocyanate-induced asthma as compared with asymptomatic-exposed controls [46] and that the amount of sHLA-G detected in the medium from PBMC stimulated with allergen in vitro is reduced after specific immunotherapy [47]. Moreover, previous studies in allergic rhinitis (AR) patients indicated that sHLA-G serum levels were: i) significantly increased in comparison with normal subjects; ii) elevated both outside and during the pollen season in patients with seasonal allergy; and iii) correlated with clinical severity, drug use, allergen-specific IgE levels, type of allergy and response to immunotherapy [48-52]. However, to the best of our present knowledge, no study has been performed to investigate the effect of immune cell exposure to allergens in vitro on HLA-G molecules in AR patients. Therefore, the aim of the present study was to evaluate the membrane expression and secretion of HLA-G molecules in immune cells from AR patients after in vitro incubation with the causal allergen as well as with non-specific stimuli.

\section{Materials and methods}

\subsection{Study population}

Twenty-two allergic patients (11 males and 11 females, mean age 36.14 years) were enrolled in the study. Inclusion criteria were: presence of allergic rhinitis, documented by history of typical nasal symptoms, positive skin prick test for the specific allergen performed according to validated criteria and demonstration of a cause/effect relationship between exposure to the sensitizing allergen and the occurrence of nasal symptoms (post hoc ergo propter hoc).

Patients with either acute upper respiratory infections, or undergoing specific immunotherapy, or using nasal or oral corticosteroids, antileukotrienes and antihistamines within the previous 4 weeks were excluded. Eighteen patients were mono-allergic to either Graminaceae (n. 5), Parietaria (n. 7) or Dermatophagoides (n. 6), whereas 4 patients were allergic to both Parietaria and Dermatophagoides. Patients were evaluated during winter, such as outside the pollen season, but when the exposure to mite was still present.

Ten healthy subjects (5 males and 5 females, mean age 38.26 years) were enrolled as controls. The study was conducted with the approval of the local Ethics Committee and after obtaining the written informed consent by all participants.

\subsection{Cell cultures}

Peripheral blood mononuclear cells (PBMC) were isolated from heparinized venous blood samples $(10 \mathrm{U} / \mathrm{mL}$ heparin) by Ficoll-Hypaque density gradient centrifugation (Lymphoflot, Biotest, Germany). PBMC were then washed with phosphate-buffered saline (PBS) and either utilized for membrane antigens assessment or cultured up to $72 \mathrm{~h}$ in 96-well U-bottomed microplates (Becton Dickinson, CA, USA) with RPMI-1640 complete medium (Biochrom AG, Germany) supplemented with $10 \%$ autologous plasma at $37^{\circ} \mathrm{C}$ in a $5 \% \mathrm{CO}_{2}$ atmosphere in humified air. PBMC were cultured in the absence (controls) or in the presence of the following stimuli or allergens (kindly provided by Anallergo, Florence, Italy): phytohemoagglutinin (PHA, $10 \mu \mathrm{g} / \mathrm{ml}$, Sigma Aldrich, Italy), lipopolisaccaride (LPS, $20 \mu \mathrm{g}$ / ml, Sigma Aldrich, Italy), phorbol-myristate-acetate (PMA, $20 \mu \mathrm{g}$ / $\mathrm{ml}$, Sigma Aldrich, Italy) + ionomycin ( $1 \mu \mathrm{M}$, Sigma Aldrich, Italy), Olea $(1 \mu \mathrm{g} / \mathrm{ml})$, Parietaria $(1 \mu \mathrm{g} / \mathrm{ml})$, Graminaceae $(1 \mu \mathrm{g} / \mathrm{ml})$, and Dermatophagoides $(2.5 \mu \mathrm{g} / \mathrm{ml})$. At the end of the incubation period, supernatants were collected and kept frozen at $-30^{\circ} \mathrm{C}$ until sHLA-G determination and cells were washed with PBS and used for membrane antigens assessment.

\subsection{Flow cytometric analysis}

Expression of cell membrane antigens was analyzed by direct immunofluorescence incubating PBMC from each individual $\left(1 \times 10^{5}\right.$ cells in $100 \mu$ of PBS $)$ with the fluorochrome-conjugated anti-HLA-G monoclonal antibody (mAb) MEM-G9 (Exbio, Czech Republic), which reacts with the native form of HLA-G1, and with the fluorochrome-conjugated anti-CD3,-CD4,-CD8,-CD11c, -CD14, -CD16, -CD19, -CD25, -CD27, -CD45, -CD45RA, -CD56, -CD123, -HLA DR (Beckman Coulter Europe) mAbs at $4{ }^{\circ} \mathrm{C}$ for $30 \mathrm{~min}$ in the dark. For Foxp3 intracellular staining, cells were permeabilized and fixed using FOXP3 Fix/Perm Buffer Set (Biolegend), according to manufacturer's instructions, then incubated with fluorochrome conjugated anti-Foxp3 $\mathrm{mAb}$ for $30 \mathrm{~min}$ at $4{ }^{\circ} \mathrm{C}$ in the dark; fluorochrome-conjugated isotype matched Abs were also used as controls. For intracellular staining, after incubation with the primary $\mathrm{mAb}$ cells were fixed and permeabilized with IntraPrep (Beckman Coulter Europe), according to the manufacturer's instructions, and blocked with $5 \%$ normal goat serum for $20 \mathrm{~min}$ on ice to prevent non-specific antibody binding. Then, anti-interleukin (IL)4, -IL10, -IL17 or $-\gamma$-interferon (IFN) (BD Biosciences) $\mathrm{mAb}$ was added at $4{ }^{\circ} \mathrm{C}$ for $30 \mathrm{~min}$ in the dark. After staining, the analysis was performed by flow cytometry using a FC500 flow cytometer equipped with CXP software (Beckman Coulter Europe).

\section{4. sHLA-G measurements}

The determination of sHLA-G molecules was performed by sandwich immunoenzymatic assays. A commercially available assay (Exbio, Czech Republic), which employs the MEM-G9 mAb as capture antibody, was utilized to determine the amount of sHLA-G1/ HLA-G5 molecules. In order to specifically determine the amount of sHLA-G1 and HLA-G5 molecules, immunoenzymatic assays were performed utilizing as capture antibodies the $01 \mathrm{G}$ and the 5A6G7 mAbs (Exbio, Czech Republic), which recognize sHLA-G1 and HLA-G5, respectively. The HRP-conjugated B2M mAb (Exbio, Czech Republic), which recognizes $\beta 2$-microglobulin, was employed as detection antibody in all assays. Plates were read with an ELX800 ELISA reader (BIO-TEK Instrument Inc.) and results were expressed as $\mathrm{U} / \mathrm{ml}$.

\subsection{Western blot analysis}

PBMC from one patient allergic to Dermatophagoides were incubated for $72 \mathrm{~h}$ in culture medium in absence or in presence of the allergens Olea and Dermatophagoides, as previously described. Monocytes, CD4+ T cells and CD8 $+\mathrm{T}$ cells were obtained by positive selection using magnetic beads coated with anti-CD14, -CD4 and -CD8 antibodies according to manufacturer's instructions (Dynabeads). The 221 cell line transfected with HLA-G $(221-\mathrm{G})$ was utilized as positive control. Cells were lysed in cold buffer (20 mM HEPES, $150 \mathrm{mM}$ $\mathrm{NaCl}, 10 \%$ [v/v] glycerol, 0.5\% [v/v] NP-40, $1 \mathrm{mM}$ EDTA, $2.5 \mathrm{mM}$ DTT, $10 \mu \mathrm{g} / \mathrm{L}$ aprotinin, leupeptin, pepstatin A, $1 \mathrm{mM} \mathrm{PMSF}$, and Na3VO4). Protein concentration was determined with the Bredford protein reagent (BioRad, USA) and $50 \mu \mathrm{g}$ were resolved by $12 \%$ SDS-polyacrylamide electrophoresis. Then, proteins were transferred on nitrocellulose membrane (GE Healthcare, Buckinghamshire, England) at $4{ }^{\circ} \mathrm{C}$ for $45 \mathrm{~min}$. After blocking for $1 \mathrm{~h}$ in $5 \%$ nonfat dry milk and washing with Tris-buffer saline-Tween 20 (10 mM Tris-base $\mathrm{pH} 7.4,150 \mathrm{mM} \mathrm{NaCl}$ and $0.05 \%$ Tween 20 ), membranes were incu- 
bated with appropriate dilutions of MEM-G1 mAb which recognizes the HLA-G heavy chain (Exbio) and anti-human actin antibody (Santa Cruz Biotechnology, Santa Cruz, CA, USA) and finally incubated with anti-mouse immunoglobulins horseradish peroxidase conjugated secondary antibody (Santa Cruz Biotechnology). Immunoblots were developed with Immobilon Western chemiluminescent HRP substrate (Millipore Billerica, MA, U.S.A.). Band intensities were determined using IAS 2000 software from Delta Sistemi (Latina, Italy).

\subsection{Statistical analysis}

Data are reported as mean $( \pm \mathrm{SD})$. Comparisons between variables were performed by two-tailed Student's $t$ test for independent samples. Statistical significance was assumed for $\mathrm{p}<0.05$.
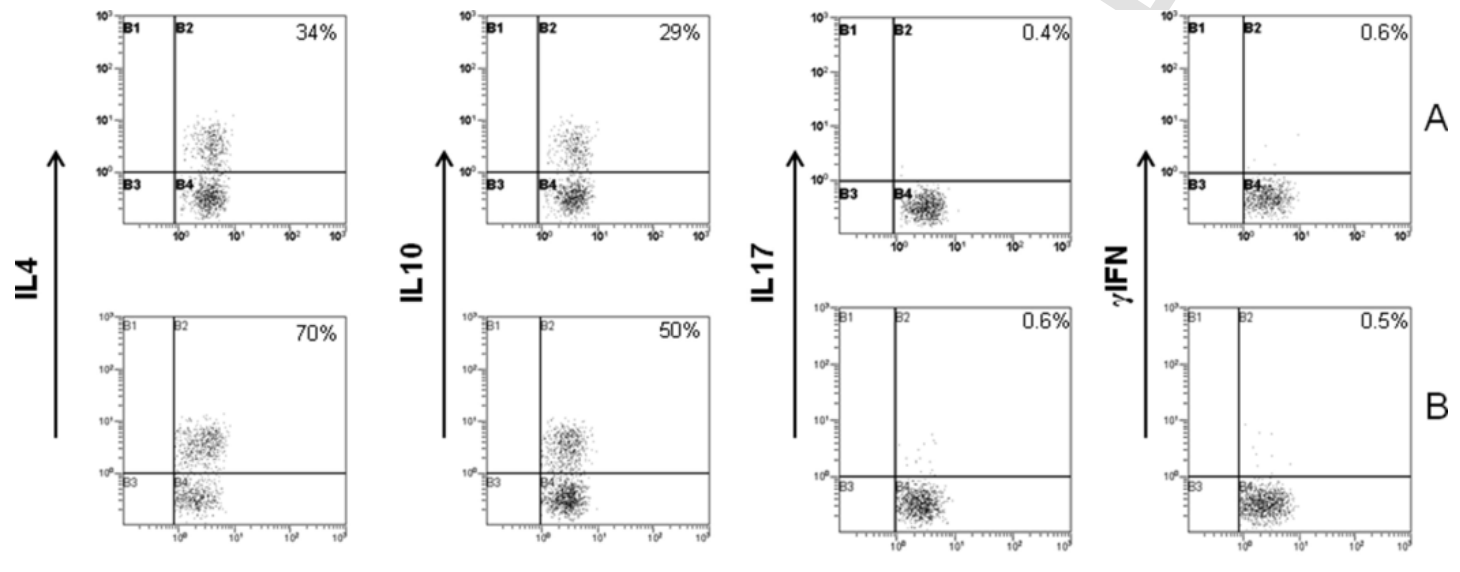

\section{CD4+HLA-G+}

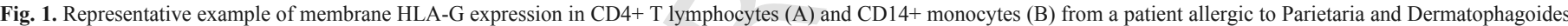

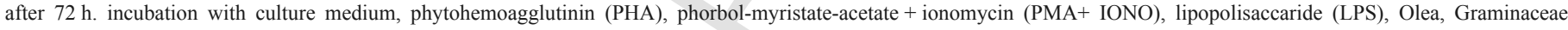
(Gram), Parietaria (Par) and Dermatophagoides (Derm).

\section{Stimulus}
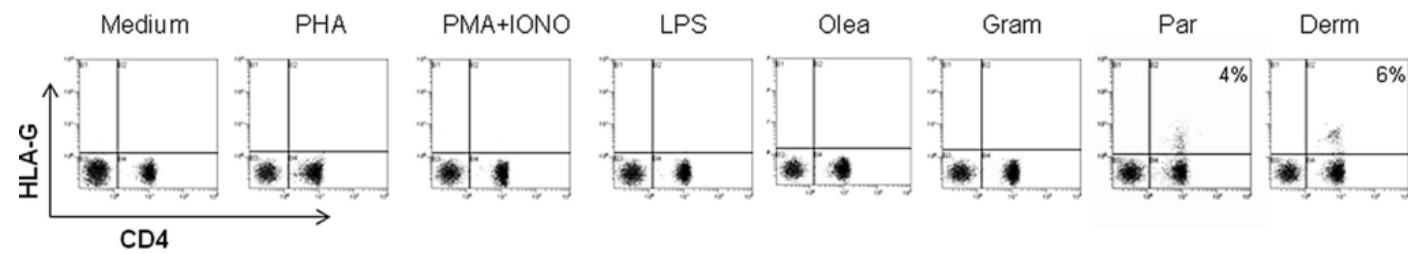

A
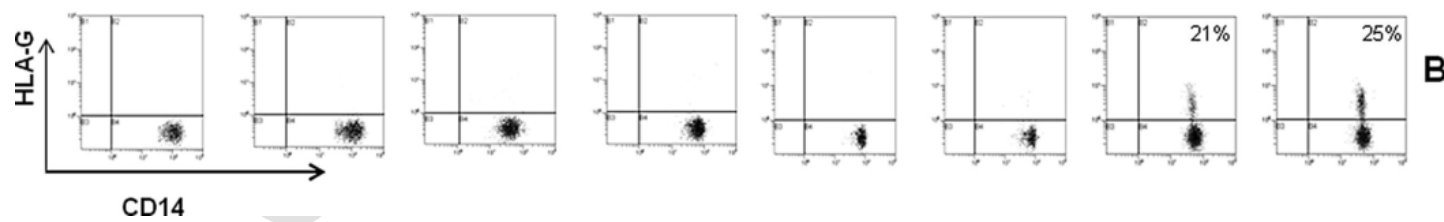

B

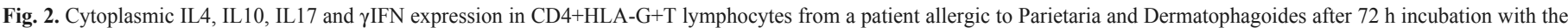
causal allergen. (A: Parietaria; B: Dermatophagoides). 
CD4+ $\mathrm{T}$ regulatory cells (Tregs) including CD4+CD25+FoxP3+, CD4+CD45RA+CD27+ naïve, CD4+CD45RA ${ }^{-}$CD27+ central memory and $\mathrm{CD} 4+\mathrm{CD} 45 \mathrm{RA}^{-} \mathrm{CD} 27^{-}$effector memory cells did not show any detectable HLA-G expression after incubation with aspecific stimuli and allergens (data not shown).

Additional experiments indicated that the percentage of HLA-G positive cells in PBMC from patients allergic to Parietaria and Dermatophagoides was significantly higher $(\mathrm{p}<0.0001)$ after $72 \mathrm{~h}$ incubation with the causal allergen than after incubation with aspecific stimuli or non causal allergens, the highest HLA-G expression being observed in monocytes from subjects allergic to Dermatophagoides (Fig. 3). This latter finding was confirmed by measuring the mean fluorescence intensity (MFI) values of HLA-G-positive cells (Table 1).
By contrast, PBMC from patients allergic to Graminaceae showed only a slight increase in the percentage of HLA-G-positive cells after incubation with the causal allergen (data not shown).

\subsection{Membrane HLA-G expression in circulating PBMC}

HLA-G expression was detected in a small number of circulating CD4+ $\mathrm{T}$ cells (about $0.5 \%$ ) and, among them, in a very low percentage (ranging from 0.1 to $0.3 \%$ ) of CD4+CD45RA+CD27+ or CD4+CD45RA ${ }^{-}$CD27+ Tregs. HLA-G expression was not detectable in circulating $\mathrm{CD} 8+, \mathrm{CD} 19+, \mathrm{CD} 56+$ cells, in CD4+CD25+FoxP3+Tregs and

\section{Patient's Allergy}

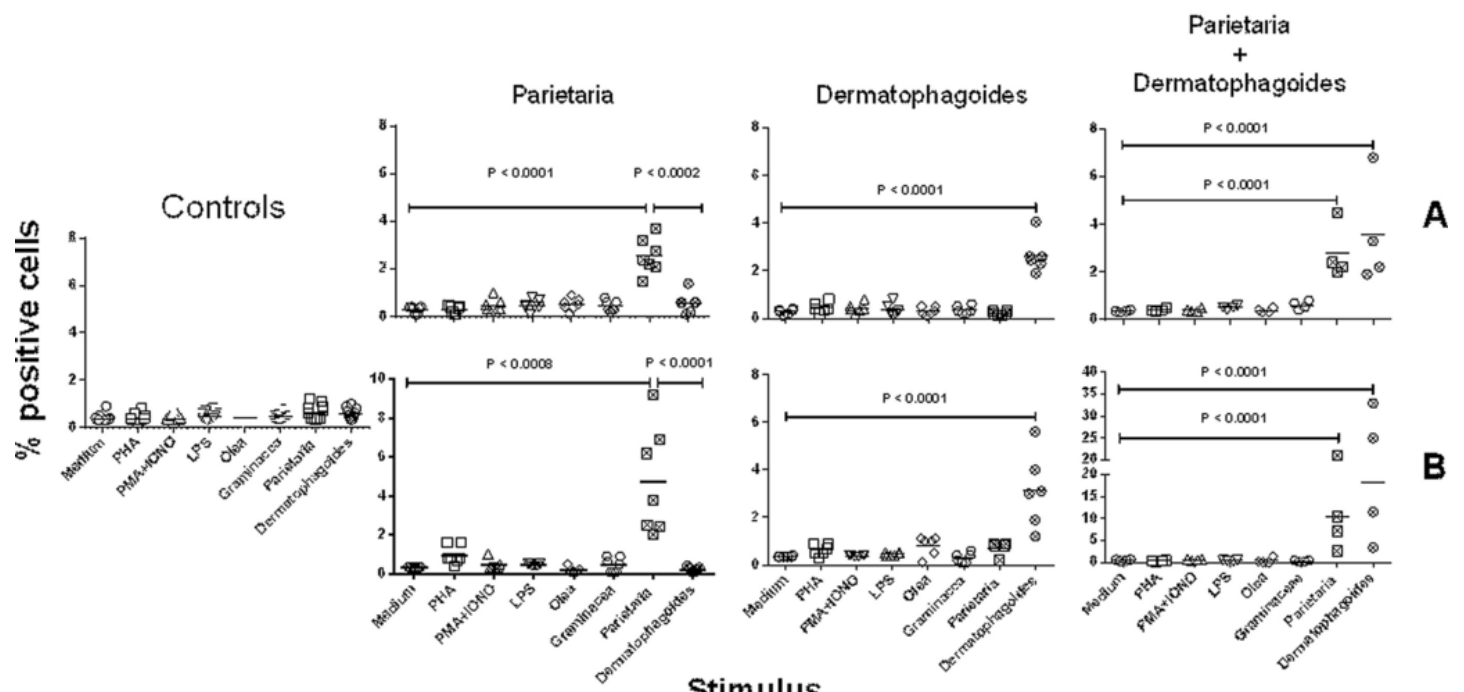

\section{Stimulus}

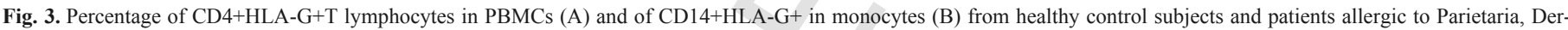
matophagoides and Parietaria + Dermatophagoides after $72 \mathrm{~h}$ incubation with different stimuli. Horizontal bars represent the mean.

Table 1

HLA-G membrane expression in CD4+ T lymphocytes (A) and in CD14+ monocytes (B).

\begin{tabular}{|c|c|c|c|c|}
\hline \multirow[t]{2}{*}{ Stimulus } & \multirow[t]{2}{*}{ Controls (n. 6) } & \multicolumn{3}{|l|}{ Patient's allegy } \\
\hline & & Parietaria (n. 6) & Dermatophagoides (n. 6) & Parietaria and Dermatophagoides (n. 4) \\
\hline \multicolumn{5}{|l|}{$A$} \\
\hline Medium & $0.35 \pm 0.02^{\S}$ & $0.36 \pm 0.02$ & $0.36 \pm 0.02$ & $0.38 \pm 0.03$ \\
\hline PHA & $0.37 \pm 0.05$ & $0.34 \pm 0.02$ & $0.35 \pm 0.03$ & $0.37 \pm 0.04$ \\
\hline PMA + ionomycin & $0.36 \pm 0.01$ & $0.37 \pm 0.05$ & $0.36 \pm 0.02$ & $0.38 \pm 0.01$ \\
\hline LPS & $0.32 \pm 0.01$ & $0.33 \pm 0.03$ & $0.35 \pm 0.04$ & $0.37 \pm 0.05$ \\
\hline Parietaria & $0.35 \pm 0.02$ & $2.17 \pm 0.53^{* *}$ & $0.34 \pm 0.01$ & $1.99 \pm 0.32^{* *}$ \\
\hline Olea & $0.37 \pm 0.03$ & $0.36 \pm 0.03$ & $0.32 \pm 0.01$ & $0.34 \pm 0.05$ \\
\hline Graminacea & $0.34 \pm 0.05$ & $0.33 \pm 0.02$ & $0.35 \pm 0.03$ & $0.36 \pm 0.04$ \\
\hline Parietaria & $0.37 \pm 0.03$ & $0.34 \pm 0.01$ & $0.36 \pm 0.05$ & $0.33 \pm 0.02$ \\
\hline Dermatophagoides & $0.34 \pm 0.01$ & $0.36 \pm 0.02$ & $2.74 \pm 0.94^{* *}$ & $1.72 \pm 0.12^{* *}$ \\
\hline \multicolumn{5}{|l|}{$B$} \\
\hline Medium & $0.33 \pm 0.01$ & $0.35 \pm 0.02$ & $0.37 \pm 0.02$ & $0.52 \pm 0.17$ \\
\hline PHA & $0.37 \pm 0.05$ & $0.36 \pm 0.04$ & $0.38 \pm 0.06$ & $0.39 \pm 0.05$ \\
\hline PMA + ionomycin & $0.35 \pm 0.02$ & $0.54 \pm 0.31$ & $0.38 \pm 0.02$ & $0.66 \pm 0.25$ \\
\hline LPS & $0.42 \pm 0.06$ & $0.40 \pm 0.04$ & $0.41 \pm 0.07$ & $0.43 \pm 0.05$ \\
\hline Olea & $0.37 \pm 0.03$ & $0.37 \pm 0.05$ & $0.36 \pm 0.04$ & $0.38 \pm 0.05$ \\
\hline Graminacea & $0.33 \pm 0.01$ & $0.32 \pm 0.01$ & $0.37 \pm 0.03$ & $0.34 \pm 0.02$ \\
\hline Parietaria & $0.34 \pm 0.01$ & $3.91 \pm 2.10^{*}$ & $0.36 \pm 0.01$ & $4.81 \pm 2.15^{*}$ \\
\hline Dermatophagoides & $0.34 \pm 0.02$ & $0.35 \pm 0.01$ & $3.00 \pm 0.85^{* *}$ & $4.34 \pm 2.65^{*}$ \\
\hline
\end{tabular}

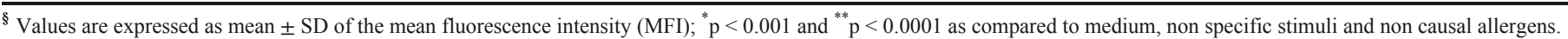


$\mathrm{CD}^{-} \mathrm{CD} 19^{-} \mathrm{CD} 16^{-} \mathrm{CD} 56^{-} \mathrm{HLA}-\mathrm{DR}+\mathrm{CD} 11 \mathrm{c}+/ \mathrm{CD} 123+$ myeloid or plasmacytoid dendritic cells (data not shown).

\section{3. sHLA-G determination in culture supernatants}

In order to analyze the kinetics of sHLA-G release in culture supernatant, preliminary experiments were performed culturing PBMC from 3 allergic patients with the causal allergen up to $120 \mathrm{~h}$. Results indicated that a progressive increase of sHLA-G molecules is detectable during the incubation period reaching its maximum after $72 \mathrm{~h}$ (data not shown).

Experiments were then performed incubating for $72 \mathrm{~h}$ PBMC from AR patients in medium alone and in medium supplemented with the causal allergen or non causal allergen. Results indicated that the amount of sHLA-G1/HLA-G5 molecules was significantly higher in the supernatant of PBMC incubated with the causal allergen ( $p$ values ranging from $<0.005$ to $<0.0001$ ) than in the supernatant of PBMC incubated with culture medium or non causal allergen (Table 2). Moreover, these experiments also defined that the supernatant of PBMC cultured with the causal allergen mainly contained HLA-G5 molecules (Table 2).

\subsection{HLA-G determination by Western blot analysis}

Western blot analysis of monocytes, CD4+ T cells and CD8+ T cells obtained from PBMC of a patient allergic to Dermatophagoides confirmed that HLA-G is detected in the membrane of monocytes and CD4+ T cells after incubation with the causal allergen, but not with non causal allergen (Fig. 4).

Table 2

sHLA-G level in culture supernatant.

\begin{tabular}{|c|c|c|c|c|}
\hline Patient's allergy & Stimulus & sHLA-G1/G5 & sHLA-G1 & sHLA-G5 \\
\hline \multirow[t]{3}{*}{ Parietaria } & Medium & $2.03 \pm 0.55^{\S}$ & $1.77 \pm 0.53$ & $0.24 \pm 0.01$ \\
\hline & Parietaria & $38.98 \pm 18.64^{* *}$ & $2.45 \pm 0.66$ & $31.41 \pm 18.00^{* *}$ \\
\hline & Dermatophagoides & $2.42 \pm 0.80$ & $1.69 \pm 0.64$ & $0.53 \pm 0.47$ \\
\hline \multirow[t]{3}{*}{ Dermatophagoides } & Medium & $2.87 \pm 0.91$ & $1.52 \pm 0.22$ & $0.25 \pm 0.01$ \\
\hline & Parietaria & $3.84 \pm 1.96$ & $1.88 \pm 0.29$ & $2.17 \pm 2.61$ \\
\hline & Dermatophagoides & $30.62 \pm 10.02^{* *}$ & $3.07 \pm 0.58$ & $23.21 \pm 4.49^{* *}$ \\
\hline \multirow[t]{3}{*}{ Parietaria and Dermatophagoides } & Medium & $1.81 \pm 0.47$ & $1.40 \pm 0.23$ & $0.23 \pm 0.02$ \\
\hline & Parietaria & $52.96 \pm 24.32^{*}$ & $3.00 \pm 0.88$ & $51.15 \pm 23.25^{*}$ \\
\hline & Dermatophagoides & $41.38 \pm 12.37^{* *}$ & $2.54 \pm 1.47$ & $40.88 \pm 13.24^{* *}$ \\
\hline
\end{tabular}

$\S^{\S}$ Values are expressed as mean $( \pm \mathrm{SD}) \mathrm{U} / \mathrm{ml} ;{ }^{*} \mathrm{p}<0.005$ and ${ }^{* *} \mathrm{p}<0.0001$ as compared to medium and/or non causal allergen.

\section{Medium}

Olea

\section{Dermatophagoides}
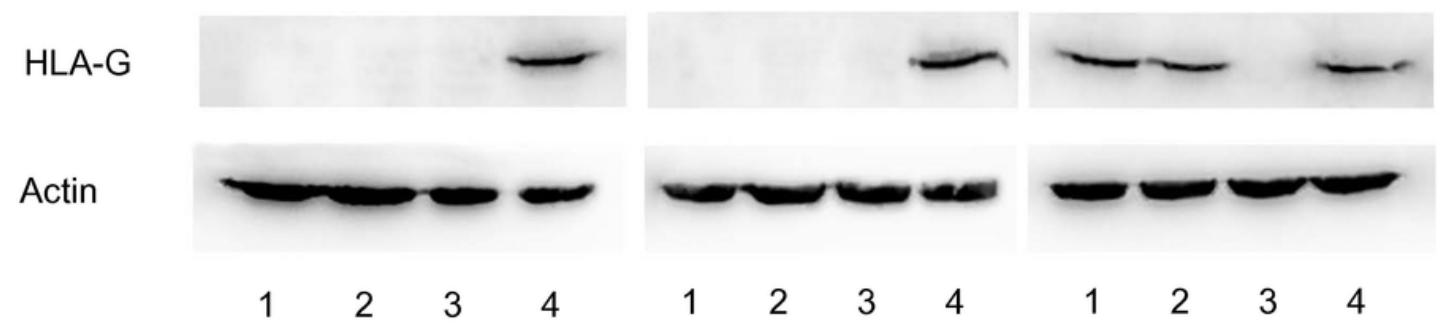

$\begin{array}{llll}1 & 2 & 3 & 4\end{array}$

123

4

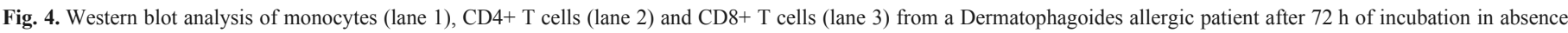
(medium) or in presence of the allergens Olea and Dermatophagoides. 221-G cells are the positive control (lane 4). 
dence, it has been suggested that sHLA-G might be considered a biomarker of allergic reaction.

The present study was aimed at evaluating the in vitro expression and release of HLA-G molecules by PBMC after incubation with both allergenic and non-allergenic stimuli in AR patients exposed or not to the causal allergen. HLA-G membrane expression was specifically induced by incubation with the causal allergen, but not by incubation with non-causal allergens or non-specific stimuli, underlining the specificity of the immune response to allergens. Of interest, only CD4+ T cells, in particular Th- 2 cells, and monocytes expressed HLA-G after allergenic challenge whereas CD8+ T lymphocytes, B lymphocytes, NK cells and Tregs did not show any detectable HLA-G expression after incubation with aspecific stimuli and allergens. Notably, monocytes expressed HLA-G at higher levels than CD4+ T lymphocytes suggesting that these cells could be the most relevant source of HLA-G production. The exposure to the causal allergen seems to be the main factor inducing HLA-G expression. In fact, patients allergic to mites, evaluated during winter when the exposure to mite was still present, showed the more intense membrane HLA-G expression, whereas grass pollen allergic patients, who were evaluated far from the pollen season, showed a very low increase of HLA-G expression.

The measurement of sHLA-G in culture supernatants confirmed the cell membrane results, the highest amount of sHLA-G molecules being found when the causal allergen was used as stimulus. Of note, soluble molecules detected in culture supernatants mainly belong to the HLA-G5 isoform strongly suggesting that they are actively secreted by immune cells after incubation with allergen.

On the basis of this in vitro study we could hypothesize that HLA-G molecules might play a role also in allergic reaction in vivo. This hypothesis is consistent with a series of in vivo studies showing that sHLA-G serum level is increased in allergic patients and correlates with clinical severity, drug use, allergen-specific IgE levels, type of allergy, and response to immunotherapy [48-52].

At present, the role of membrane bound and soluble HLA-G molecules in immunoregulation appears complex and not univocal. In fact, although HLA-G molecules mainly exert immunosuppressive effects [28-33], they may also play an immunoregulatory role [36-39] by tuning immune responses towards either a Th- 2 or a Th- 1 cytokine profile $[34,35]$. Accordingly, it has been recently proposed that HLA-G should be no longer qualified as a "shield" to protect tissues and cells from immune destruction but, rather, as an "immune checkpoint" molecule [53]. The results of our in vitro experiments may suggest that the expression and secretion of HLA-G molecules may contribute to the Th-2 shift which characterizes the allergic reaction.

In conclusion, the present study provides the first in vitro evidence that: i) HLA-G is specifically expressed and released by PBMC after stimulation with the causal allergen; ii) the main source of HLA-G molecules are monocytes and, to a lesser extent, CD4+ Th-2 cells; iii) the natural allergen exposure significantly affects HLA-G expression and release. Further studies are needed to better clarify the functional role of HLA-G in allergic diseases.

\section{References}

[1] S.A. Ellis, M.S. Palmer, A.J. McMichael, Human trophoblast and the choriocarcinoma cell line BeWo express a truncated HLA class I molecule, J. Immunol. 144 (1990) 731-735.

[2] T.V. Hviid, L.G. Larsen, A.M. Hoegh, M. Bzorek, HLA-G expression in placenta in relation to HLA-G genotype and polymorphisms, Am. J. Reprod. Immunol. 52 (2004) 212-217.

[3] S. Kovats, E.K. Main, C. Librach, M. Stubblebine, S.J. Fisher, R. DeMars, A class I antigen, HLA-G, expressed in human trophoblasts, Science 144 (1990) $220-223$.
[4] L. Crisa, M.T. McMaster, J.K. Ishii, S.J. Fisher, D.R. Salomon, Identification of a thymic epithelial cell subset sharing expression of the class Ib HLA-G molecule with fetal trophoblasts, J. Exp. Med. 186 (1997) 289-298.

[5] M. Le Discorde, P. Moreau, P. Sabatier, J.M. Legeais, E.D. Carosella, Expression of HLA-G in human cornea, an immune-privileged tissue, Hum. Immunol. 64 (2003) 1039-1044.

[6] V. Cirulli, J. Zalatan, M. McMaster, R. Prinsen, D.R. Salomon, C. Ricordi, et al., The class I HLA repertoire of pancreatic islets comprises the nonclassical class Ib antigen HLA-G, Diabetes 55 (2006) 1214-1222.

[7] O. Brugière, G. Thabut, M. Pretolani, I. Krawice-Radanne, C. Dill, A. Herbreteau, et al., Immunohistochemical study of HLA-G expression in lung transplant recipients, Am. J. Transplant. 9 (2009) 1427-1438.

[8] Y. Yang, W. Chu, D.E. Geraghty, J.S. Hunt, Expression of HLA-G in human mononuclear phagocytes and selective induction by IFN-gamma, J. Immunol. 156 (1996) 4224-4231.

[9] C. Menier, M. Rabreau, J.C. Challier, M. Le Discorde, E.D. Carosella, N. Rouas-Freiss, Erythroblasts secrete the nonclassical HLA-G molecule from primitive to definitive hematopoiesis, Blood 104 (2004) 3153-3160.

[10] E.D. Carosella, B. Favier, N. Rouas-Freiss, P. Moreau, J. LeMaoult, Beyond the increasing complexity of the immunomodulatory HLA-G molecule, Blood 111 (2008) 4862-4870.

[11] E. Fainardi, M. Castellazzi, M. Stignani, F. Morandi, G. Sana, R. Gonzalez, et al., Emerging topics and new perspectives on HLA-G, Cell. Mol. Life Sci. 68 (2011) 433-451.

[12] P. Paul, F.A. Cabestre, E.C. Ibrahim, S. Lefevbre, I. Khalil-Daher, G. Vazeux, et al., Identification of HLA-G7 as a new slice variant of the HLA-G mRNA and expression of soluble HLA-G5, -G6, and -G7 transcripts in human transfected cells, Hum. Immunol. 61 (2000) 1138-1149.

[13] V. Rebmann, J. LeMaoult, N. Rouas-Freiss, E. Carosella, H. Grosse-Wilde, Quantification and identification of soluble HLA-G isoforms, Tissue Antigens 69 (Suppl. 1) (2007) 143-149.

[14] W.B. Tabayoyong, N. Zavazava, Soluble HLA revisited, Leuk. Res. 31 (2007) $121-125$.

[15] B. Riteau, F. Faure, C. Menier, S. Viel, E.D. Carosella, S. Amigorena, et al., Exosomes bearing HLA-G are released by melanoma cells, Hum. Immunol. 64 (2003) 1064-1072.

[16] E. Alegre, V. Rebmann, J. Lemaoult, C. Rodriguez, P.A. Horn, A. Díaz-Lagares, et al., In vivo identification of an HLA-G complex as ubiquitinated protein circulating in exosomes, Eur. J. Immunol. 43 (2013) 1933-1939.

[17] S.K. Kshirsagar, S.M. Alam, S. Jasti, H. Hodes, T. Nauser, M. Gilliam, et al., Immunomodulatory molecules are released from the first trimester and term placenta via exosomes, Placenta 33 (2012) 982-990.

[18] E.D. Carosella, P. Moreau, S. Aractingi, N. Rouass-Freiss, HLA-G: a shield against inflammatory aggression, Trends Immunol. 10 (2001) 553-555.

[19] V. Pistoia, F. Morandi, X. Wang, S. Ferrone, Soluble HLA-G: are they clinically relevant?, Semin. Cancer Biol. 17 (2007) 469-479.

[20] E.D. Carosella, P. Moreau, J. LeMaoult, N. Rouas-Freiss, HLA G: from biology to clinical benefits, Trends Immunol. 29 (2008) 125-132.

[21] G. Murdaca, P. Contini, M. Setti, P. Cagnati, F. Lantieri, F. Indiveri, et al., Behavior of non-classical soluble HLA class $\mathrm{G}$ antigens in human immunodeficiency virus 1-infected patients before and after HAART: comparison with classical soluble HLA-A, -B, -C antigens and potential role in immune-reconstitution, Clin. Immunol. 133 (2009) 238-244.

[22] C. Menier, N. Rouas-Freiss, B. Favier, J. LeMaoult, P. Moreau, E.D. Carosella, Recent advances on the non-classical major histocompatibility complex class I HLA-G molecule, Tissue Antigens 75 (2009) 201-206.

[23] P.J. Weng, Y.M. Fu, S.X. Ding, D.P. Xu, A. Lin, W.H. Yan, Elevation of plasma soluble human leukocyte antigen-G in patients with chronic hepatitis $\mathrm{C}$ virus infection, Hum. Immunol. 72 (2011) 406-411.

[24] E. Fainardi, R. Rizzo, L. Melchiorri, M. Stignani, M. Castellazzi, C. Tamborino, et al., CSF levels of soluble HLA-G and Fas molecules are inversely associated to MRI evidence of disease activity in patients with relapsing-remitting multiple sclerosis, Mult. Scler. 14 (2008) 446-454.

[25] E.D. Carosella, The tolerogenic molecule HLA-G, Immunol. Lett. 138 (2011) $22-24$.

[26] A. Gonzalez, V. Rebmann, J. LeMaoult, P.A. Horn, E.D. Carosella, E. Alegre, The immunosuppressive molecule HLA-G and its clinical implications, Crit. Rev. Clin. Lab. Sci. 49 (2012) 63-84.

[27] N. Rouas-Freiss, R.M. Gonçalves, C. Menier, J. Dausset, E.D. Carosella, Direct evidence to support the role of HLA-G in protecting the fetus from maternal uterine natural killer cytolysis, Proc. Natl. Acad. Sci. U.S.A. 94 (1997) $11520-11525$.

[28] P. Contini, M. Ghio, A. Poggi, G. Filaci, F. Indiveri, S. Ferrone, et al., Soluble HLA-A, -B, -C, and -G molecules induce apoptosis in T and NK CD8+ cells and inhibit cytotoxic T cell activity through CD8 ligation, Eur. J. Immunol. 33 (2003) 125-134

[29] N. Lila, N. Rouas-Freiss, J. Dausset, A. Carpentier, E.D. Carosella, Soluble HLA-G protein secreted by allo-specific CD4+ T cells suppresses the 
allo-proliferative response: a CD4+ T cell regulatory mechanism, Proc. Natl. Acad. Sci. U.S.A. 98 (2001) 12150-12155.

[30] G. Le Friec, B. Laupeze, O. Fardel, Y. Sebti, C. Pangault, V. Guilloux, et al., Soluble HLA-G inhibits human dendritic cell-triggered allogeneic T-cell proliferation without altering dendritic differentiation and maturation processes, Hum. Immunol. 64 (2003) 752-761.

[31] A. Naji, C. Menier, F. Morandi, S. Agaugué, G. Maki, E. Ferretti, et al., Binding of HLA-G to ITIM-bearing Ig-like transcript 2 receptor suppresses B cell responses, J. Immunol. 192 (2014) 1536-1546.

[32] S. Fournel, M. Aguerre-Gir, X. Huc, F. Lenfant, A. Alam, A. Toubert, et al., Cutting edge: soluble HLA-G1 triggers CD95/CD95 ligand-mediated apoptosis in activated CD8+ cells by interacting with CD8, J. Immunol. 164 (2000) 6100-6104.

[33] P. Contini, M. Ghio, M. Merlo, A. Poggi, F. Indiveri, F. Puppo, Apoptosis of antigen-specific T lymphocytes upon the engagement of CD8 by soluble HLA class I molecules is Fas Ligand/Fas mediated: evidence for the involvement of p561ck, calcium calmodulin kinase II, and calcium-independent protein kinase $\mathrm{C}$ signaling pathways and for NF- $\mathrm{KB}$ and NF-AT nuclear translocation, J. Immunol. 175 (2005) 7244-7254.

[34] T. Kanai, T. Fujii, S. Kozuma, T. Yamashita, A. Miki, A. Kikuchi, et al., Soluble HLA-G influences the release of cytokines from allogeneic peripheral blood mononuclear cells in culture, Mol. Hum. Reprod. 7 (2001) 195-200.

[35] T. Kanai, T. Fujii, N. Unno, T. Yamashita, H. Hyodo, A. Miki, et al., Human leukocyte antigen-G-expressing cells differently modulate the release of cytokines from mononuclear cells present in the decidua versus peripheral blood, Am. J. Reprod. Immunol. 45 (2001) 94-99.

[36] J. LeMaoult, J. Caumartin, M. Daouya, B. Favier, S. Le Rond, A. Gonzalez, et al., Immune regulation by pretenders: cell-to-cell transfers of HLA-G make effector T cells act as regulatory cells, Blood 109 (2007) 2040-2048.

[37] U. Feger, E. Tolosa, Y.H. Huang, A. Waschbisch, T. Biedermann, A. Melms, et al., HLA-G expression defines a novel regulatory T-cell subset present in human peripheral blood and sites of inflammation, Blood 110 (2007) 568-577.

[38] Y.H. Huang, A.L. Zozulya, C. Weidenfeller, I. Metz, D. Buck, K.V. Toyka, et al., Specific central nervous system recruitment of HLA-G regulatory T cells in multiple sclerosis, Ann. Neurol. 66 (2009) 171-183.

[39] E.D. Carosella, S. Gregori, J. LeMaoult, The tolerogenic interplay(s) among HLA-G, myeloid APCs, and regulatory cells, Blood 118 (2011) 6499-6505.

[40] S. Romagnani, Immunologic influences on allergy and the TH1/TH2 balance, J. Allergy Clin. Immunol. 113 (2004) 395-400.
[41] D.T. Umetsu, R.H. DeKruyff, The regulation of allergy and asthma, Immunol. Rev. 212 (2006) 238-255.

[42] F. Tahan, T. Patroglu, Plasma soluble human leukocyte antigen G levels in asthmatic children, Int. Arch. Allergy Immunol. 141 (2006) 213-216.

[43] X.Q. Zheng, C.C. Li, D.P. Xu, A. Lin, W.G. Bao, G.S. Yang, et al., Analysis of the plasma soluble human leukocyte antigen-G and interleukin-10 levels in childhood atopic asthma, Hum. Immunol. 71 (2010) 982-987.

[44] S.R. White, Human leucocyte antigen-G: expression and function in airway allergic disease, Clin. Exp. Allergy 42 (2011) 208-217.

[45] J. Nicodemus-Johnson, B. Laxman, R.K. Stern, J. Sudi, C.N. Tierney, L. Norwick, et al., Maternal asthma and microRNA regulation of soluble HLA-G in the air way, J. Allergy Clin. Immunol. 131 (2013) 1496-1503.

[46] C.E. Mapp, S. Ferrazzoni, R. Rizzo, D. Miotto, M. Stignani, P. Boschetto, et al., Soluble human leucocyte antigen-G and interleukin-10 levels in isocyanate-induced asthma, Clin. Exp. Allergy 39 (2009) 812-819.

[47] A.E. Sørensen, C.R. Johnsen, L.T. Dalgaard, P.A. Würtzen, B. Kristensen, M.H. Larsen, et al., Human leukocyte antigen-G and regulatory $\mathrm{T}$ cells during specific immunotherapy for pollen allergy, Int. Arch. Allergy Immunol. 162 (2013) $237-252$.

[48] G. Ciprandi, B.M. Colombo, P. Contini, P. Cagnati, A. Pistorio, F. Puppo, et al., Soluble HLA-G and HLA-A,-B,-C serum levels in patients with allergic rhinitis, Allergy 63 (2008) 1335-1338.

[49] G. Ciprandi, P. Contini, D. Fenoglio, M.P. Sormani, S. Negrini, F. Puppo, et al., Relationship between soluble HLA-G and HLA-A,-B,-C serum levels and IFN-gamma production after sublingual immunotherapy in patients with allergic rhinitis, Hum. Immunol. 69 (2008) 510-512.

[50] G. Ciprandi, P. Contini, A. Pistorio, G. Murdaca, F. Puppo, Sublingual immunotherapy reduces soluble HLA-G and HLA-A,-B,-C serum levels in patients with allergic rhinitis, Int. Immunopharmacol. 9 (2009) 253-257.

[51] G. Ciprandi, D. Fenoglio, I. Cirillo, A. Vizzaccaro, A. Ferrera, M.A. Tosca, F. Puppo, et al., Induction of interleukin 10 by sublingual immunotherapy for house dust mites: a preliminary report, Ann. Allergy Asthma Immunol. 95 (2005) 38-44.

[52] G. Ciprandi, A. Corsico, P. Pisati, Serum-soluble HLA-G is associated with specific IgE in patients with allergic rhinitis and asthma, Inflammation 37 (2014) 1630-1634.

[53] E.D. Carosella, N. Rouas-Freiss, D.T. Roux, P. Moreau, J. LeMaoult, HLA-G: an immune checkpoint molecule, Adv. Immunol. 127 (2015) 33-144. 